\title{
MULHERES EMPREENDEDORAS: COMPREENSÕES DO EMPREENDEDORISMO E DO EXERCÍCIO DO PAPEL DESEMPENHADO POR HOMENS E MULHERES EM ORGANIZAÇÕES
}

\author{
Anna Beatriz Cautela Tvrzká de Gouvêa - Universidade Anhembi Morumbi ${ }^{1}$ \\ Amelia Silveira - Universidade Nove de Julho ${ }^{2}$ \\ Hilka Vier Machado - Universidade Estadual de Maringá ${ }^{3}$
}

Resumo: Pesquisas com mulheres que empreendem têm sido desenvolvidas em número cada vez maior para compreender o perfil e o papel por elas desempenhado em suas empresas. Esta pesquisa exploratória, com método qualitativo, foi realizada com gestoras filiadas à Câmara da Mulher Empresária, em uma associação empresarial em Santa Catarina, caracterizando-se inicialmente o perfil pessoal e profissional de 21 mulheres. Destas, nove foram selecionadas para participar de um grupo de foco, onde manifestaram o entendimento sobre o empreendedorismo. Os resultados apontam que características pessoais e profissionais se coadunam com estudos anteriores. As verbalizações no grupo de foco evidenciam que as noções sobre empreendedorismo abrangem elementos como inovação, criatividade, oportunidade e criação de valor, tal como consta na literatura. Deixam entrever ainda compreensões acerca de diferenças quanto ao desempenho empresarial de homens e mulheres. O entendimento revela que para os homens a objetividade é predominante, enquanto que para as mulheres o exercício múltiplo de papéis e a tentativa de propiciar satisfação aos envolvidos foram ressaltados, entre outros pontos. Há destaque para a necessidade de ampliar as pesquisas, nesta temática.

Palavras-chave: Mulheres que empreendem; Perfil Empreendedor; Desempenho.

\section{WOMEN ENTREPRENEURS: UNDERSTANDINGS OF ENTREPRENEURSHIP AND OF EXERCISE OF THE ROLE PLAYED BY WOMEN AND MEN IN ORGANIZATIONS}

Abstract: Research with women who undertake have been developed in increasing numbers to understand the profile and the role they play in their companies. This exploratory research with a qualitative method was performed with the Chamber of Affiliated Managers Business Woman in a business association in Santa Catarina, initially characterized the personal and professional profiles of 21 women. Of these, nine were selected to participate in a focus group, which expressed understandings

\footnotetext{
${ }^{1}$ E.mail: abcautela@.hotmail.com

2 E.mail: ameliasilveira@gmail.com

3 E.mail: hilkavier@yahoo.com - Endereço: Avenida Colombo 5790 - zona 07 - CEP: 87020-900 Maringá, PR.
}

GOUVÊA, A. B. C. T.; SILVEIRA, A.; MACHADO. H. P. V Mulheres empreendedoras: compreensões do empreendedorismo e do exercício do papel desempenhado por homens e mulheres em organizações. Revista de Empreendedorismo e Gestão de Pequenas Empresas, v. 2, n.2, p. 32-54, 2013. 
about entrepreneurship. The results indicate that personal and professional characteristics are consistent with previous studies. Verbalizations in the focus group show that the notions of entrepreneurship covering elements such as innovation, creativity, opportunity and value creation as given in the literature. Glimpse further insights about differences in business performance of men and women. The understanding shows that for men objectivity is predominant, whereas for women the multiple roles of exercise and an attempt to provide satisfaction to those involved were highlighted, among other issues. There is emphasis on the need to expand research on this topic.

Keywords: Women Entrepreneur; Profile Entrepreneur; Performance.

\section{Introdução}

Ao analisar a história da mulher na sociedade, entende-se que sua participação deu-se recentemente, a começar pelo fato de que só adquiriram o direito ao voto em 1917, conforme Ribeiro (2008). Até esta data, a luta iniciada pelo médico e intelectual baiano César Zama recebeu como resposta em 27 de janeiro de 1891 que:

[...] a maioria do Congresso Constituinte, apesar da brilhante e vigorosa dialética exibida, em prol da mulher-votante, não quis a responsabilidade de arrastar para o turbilhão das paixões políticas a parte serena e angélica do gênero humano.

Com esta breve introdução, pode-se ter ideia de como a entrada da mulher no mercado de trabalho foi tardia e se constituiu em uma verdadeira batalha, sendo que esta conquista deve ser renovada quase que diariamente. Diversos são os relatos, em pleno século $\mathrm{XXI}$, de dificuldades e diferenças entre gêneros, quanto às características, personalidade, perfil, modo de ser, de agir e de sentir, dentre tantos outros aspectos. Vale mencionar a forma de gerenciar negócios, que também apresenta toda uma diferenciação, merecendo estudos mais aprofundados.

No tocante às mulheres que desempenham funções em empresas, estes estudos são oportunos e estão em desenvolvimento. A busca constante da mulher empresária por novos desafios torna o empreendedorismo feminino uma temática que desperta natural interesse de estudo atualmente. As mulheres hoje estão

GOUVÊA, A. B. C. T.; SILVEIRA, A.; MACHADO. H. P. V Mulheres empreendedoras: compreensões do empreendedorismo e do exercício do papel desempenhado por homens e mulheres em organizações. Revista de Empreendedorismo e Gestão de Pequenas Empresas, v. 2, n.2, p. 32-54, 2013. 
criando novas empresas, na maioria das vezes, micro e pequenas empresas que respondem por uma parcela significativa de emprego e renda, principalmente em países em desenvolvimento.

O Global Entrepreneurhip Monitor (GEM), iniciado em 1999 pela Babson College e pela London Business School, constitui-se em um programa que pesquisa o nível de atividade empreendedora no mundo, incluindo avaliações anuais. No início, cobria apenas dez países. No relatório de 2008, quarenta e três países foram analisados, entre eles o Brasil. De acordo com este relatório, a mulher brasileira vem conquistando espaço na economia contemporânea, sendo que $42 \%$ dos negócios são comandados por elas.

Nessa linha, as mulheres brasileiras ocupam o 6ํlugar no ranking mundial, sendo que deste total, $10,81 \%$ delas têm negócios, ficando atrás apenas das venezuelanas $(23,8 \%)$, tailandesas $(19,3 \%)$, jamaicanas $(15,6 \%)$, neozelandesas $(13,7 \%)$ e chinesas (11,6\%). Quando essa análise é conjunta (homens e mulheres), a classificação do Brasil está em 7ํㅡ lugar, com 11,3\% de empreendedores com empresa própria. Os empreendedores do sexo masculino aparecem em 13ํㅣㅁ luar. Esses dados invertem uma tendência histórica quando considerado o ano de 2001, onde os homens empreendedores representavam $71 \%$ e as mulheres $29 \%$ (GEM, 2008).

A atuação de mulheres no papel empreendedor tem aumentado não apenas no Brasil, mas no mundo todo. Um dos desdobramentos deste fato é o de que o estudo com mulheres empreendedoras tornou-se um tópico de pesquisas em Empreendedorismo. Conferências internacionais sobre o assunto, como a da Babson Conference ou o encontro promovido pelo International Council of Small Business (ICSB), mantém uma área específica para submissão de trabalhos sobre Mulheres Empreendedoras.

Nesse sentido, a questão que deu origem a presente pesquisa pauta-se sobre a compreensão do fenômeno empreendedor por mulheres. Ou seja, será que compreensões do empreendedorismo e do exercício do papel desempenhado por homens e mulheres em organizações. Revista de Empreendedorismo e Gestão de Pequenas Empresas, v. 2, n.2, p. 32-54, 2013. 
empreendedoras tem um entendimento do empreendedorismo que abrange alguma especificidade de gênero?

Buscando ampliar conhecimentos sobre a atuação de empreendedoras, escolheu-se como campo de estudos a Câmara da Mulher Executiva (CME) de uma associação empresarial de Santa Catarina. Esta, surgiu por iniciativa de um grupo de mulheres empresárias com o intuito de ser um núcleo que as representasse em seus interesses, promovesse trocas de experiências, desenvolvimento, integração e oportunidade de negócios.

A Câmara tem como missão: "aprimorar o conhecimento de suas integrantes em nível pessoal e profissional e oportunizar negócios entre as empresas" e como visão: "tornar-se referência pelo trabalho participativo e profissional que desenvolve junto às suas associadas e a comunidade". Os principais objetivos são: formar novas lideranças, incentivar o associativismo, aumentar a participação da mulher em uma associação mista, promover a atualização empresarial através de seminários e palestras, trocar experiências e promover negócios entre as associadas e com câmaras de outras cidades.

Estudos anteriores como, por exemplo, o de Machado (2002), Nunes (2006), Silveira, Gouvêa e Hoeltgebaum (2008), e Machado et al. (2008), foram também desenvolvidos com empreendedoras em associações empresariais e obtiveram resultados satisfatórios.

Sendo assim, a presente pesquisa apresentou como objetivo caracterizar empresárias participantes de uma associação empresarial em Santa Catarina quanto ao perfil pessoal e profissional, como também conhecer o entendimento delas sobre empreendedorismo. Este estudo reveste-se de importância na medida em que pretende contribuir para a produção científica de empreendedorismo feminino, aumentado a compreensão sobre as mulheres empresárias e o aporte do empreendedorismo neste contexto de conhecimento.

Antes de detalhar o método e descrever os resultados da pesquisa, algumas considerações sobre estudos anteriores acerca de mulheres empreendedoras foram compreensões do empreendedorismo e do exercício do papel desempenhado por homens e mulheres em organizações. Revista de Empreendedorismo e Gestão de Pequenas Empresas, v. 2, n.2, p. 32-54, 2013. 
mencionadas como fundamentação para nortear a noção do foco dos estudos no campo.

\section{Comentários sobre Estudos Anteriores com Empreendedoras}

O estudo de Schwartz (1976) foi um dos pioneiros sobre mulheres empreendedoras, centrando-se em dificuldades enfrentadas por elas, como problemas na concessão de crédito e discriminação quanto à lucratividade de seus negócios.

Neider (1997) mostra que estudos com empreendedoras enfatizam: 1) características pessoais das empreendedoras; 2) questões específicas, barreiras enfrentadas; e 3) características de suas organizações. Posteriormente, o número de pesquisas não parou de crescer e tem enfatizado diferentes aspectos, que serão destacados a seguir.

\section{Razões para Criação da Empresa}

Langowitz e Minniti (2007) investigaram que os fatores determinam a propensão das mulheres para iniciar as suas próprias empresas e verificaram se estes fatores variam em relação a países e gênero. Os itens investigados foram: propensão das mulheres para iniciarem empresas, fatores como idade, renda, estatuto de emprego, educação, conhecer outros empresários, alerta a oportunidades, receio de fracasso e importância relativa das variáveis sociodemográfica e percepção. Testaram as hipóteses com dados extraídos do banco de dados do Global Entrepreneurship Monitor (GEM) e empregaram sete modelos para testar a validade dos resultados, abrangendo 17 países e diferentes tipos de empresárias.

Como resultados obtiveram o que segue: (1) os fatores como idade, renda, estatuto de emprego e a educação tiveram incidências na propensão das mulheres compreensões do empreendedorismo e do exercício do papel desempenhado por homens e mulheres em organizações. Revista de Empreendedorismo e Gestão de Pequenas Empresas, v. 2, n.2, p. 32-54, 2013. 
para se tornarem empresárias; (2) a percepção de oportunidade, de autoconfiança e de conhecer outros empresários influencia positivamente as mulheres a iniciar as suas próprias empresas; (3) as mulheres eram menos favoráveis do que os homens em suas percepções como empresárias quanto ao ambiente de negócios e registros de medo de falhar. Os resultados foram semelhantes em todos os países.

Manolova, Brush e Edelman (2008) examinaram diferenças de motivações para iniciar uma empresa entre homens e mulheres em 441 casos. Os resultados desejados com a abertura de um novo negócio diferem por gênero. As conclusões indicam que os homens são motivados por ganhos financeiros, autorrealização e autonomia, enquanto para as mulheres o status é um fator de motivação adicional significativo.

\section{Perfil das Empreendedoras e das Empresas}

Dhaliwal (2006) compilou resultados de estudos realizados com empreendedoras inglesas, australianas, canadenses e americanas, principalmente nos seguintes pontos: perfil das mulheres, a natureza do setor de atuação, localização da empresa, número de funcionários, duração das empresas, decisão da entrada nos negócios e se houve algum tipo de aval ou suporte de agências financeiras. Os resultados sugerem que: (1) as mulheres tendem a iniciar empresas, principalmente entre 20 até 40 anos de idade; (2) os principais desafios enfrentados pelas mulheres foram: falta de confiança e pressões financeiras; (3) os motivos para começar um negócio variam de financeiros à independência e flexibilidade, cuidarem de crianças e escolha de estilo de vida; (4) a mais importante fonte de capital inicial foi economia pessoal, seguida de família e, por último, bancos ou instituições financeiras; (5) as áreas mais comuns em que as mulheres começaram suas empresas foram coaching, serviços empresariais, vendas, marketing, relações públicas, mídia, publicidade, ensino e formação. Um número significativo estava em informática e computação; (6) grande parte das respondentes tem graduação ou 
pós-graduação; (7) um número significativo das respondentes tem filhos em idade que demanda maior atenção.

\section{Decisão e Risco}

Leite (1998) menciona que, como mulheres tendem a ouvir mais outras pessoas e a levar em consideração a opinião de todos os integrantes da empresa antes de tomarem uma decisão, acabam por serem mais lentas no processo decisório.

Tan (2008) comparou as orientações empreendedoras e o desempenho entre homens e mulheres empreendedores da indústria de eletrônicos chinesa em 53 empresas. Utilizou como base as dimensões empreendedoras: visão de futuro, inovação, pró-atividade, competição acirrada e assumir riscos. Os resultados revelaram que enquanto as mulheres são influenciadas pelos mesmos fatores que afetam as decisões masculinas e exibem algumas similaridades, diferem dos homens na sua vontade de assumir mais riscos e são mais audaciosas em relação aos retornos dos investimentos e em criar vantagem competitiva futura.

\section{Crescimento e Financiamento das Empresas}

Watson (2003) mostrou que empresas comandadas por mulheres, geralmente, têm resultados menores que as comandadas por homens em vários aspectos, tais como: taxas de receitas, lucro, crescimento e falência. Enquanto as taxas de falência das empresas de mulheres são mais elevadas em comparação com as empresas de homens. $\mathrm{Na}$ indústria a situação se inverte com resultados e serviços acima da média.

Num estudo empírico com 600 empresas britânicas, Carter e Rosa (1998) mostram as diferenças de gênero quantificáveis em certas áreas de financiamento de negócio, embora as semelhanças intrassetoriais demonstram que o gênero é compreensões do empreendedorismo e do exercício do papel desempenhado por homens e mulheres em organizações. Revista de Empreendedorismo e Gestão de Pequenas Empresas, v. 2, n.2, p. 32-54, 2013. 
apenas uma das inúmeras variáveis que afetam o processo de financiamento. Carland, Carland e Card (2005) evidenciaram que as mulheres têm encontrado diversas alternativas para explorar o empreendedorismo e atingir o sucesso. Elas estão aprendendo a equilibrar as várias demandas para o seu tempo e encontrando força nos números por colaborar umas com as outras. Contudo, elas apresentam maior dificuldade em obter financiamento para suas empresas.

Para Morris et al. (2006), nos últimos anos, o número de mulheres donas de empresas com funcionários expandiu três vezes em relação a todas as empresas empregadoras. Mesmo assim, as mulheres continuam sendo sub-representadas em proporção às empresas de crescimento elevado. Para tanto, desenvolveram uma pesquisa com uma amostra de empreendedoras para avaliar motivos, obstáculos, objetivos, aspirações, necessidades e identidade do negócio. Em termos de descobertas quantitativas, o crescimento das operações estava associado com: o fato de a mulher ter sido "empurrada" ou "puxada" para o empreendedorismo; se era motivada por riqueza ou fatores de realização; se havia uma identidade forte no negócio; se tinham sócios com condições iguais; e se acreditavam que as mulheres enfrentavam obstáculos únicos para as vendas.

A pesquisa deixou claro que as empreendedoras de companhias com crescimento modesto e elevado diferem no modo como elas veem a si próprias, suas famílias, seus negócios e todo o ambiente. Os resultados de ambos os estágios sugerem que crescimento é uma escolha deliberada e que as mulheres têm um senso claro de custos e benefícios, decidindo transações de risco de forma cuidadosamente.

Manolova et al. (2007) analisam os efeitos do capital humano e a expectativa de crescimento de negócios entre homens e mulheres empresários, com 544 novos empresários na Bulgária. Os autores sugerem que a expectativa de crescimento entre os empresários é significativa e positivamente associada aos contatos de suas redes de contatos. Entre as empresárias, a expectativa de crescimento é compreensões do empreendedorismo e do exercício do papel desempenhado por homens e mulheres em organizações. Revista de Empreendedorismo e Gestão de Pequenas Empresas, v. 2, n.2, p. 32-54, 2013. 
significativa e positivamente associada à percepção de benefícios de experiência prévia.

\section{Estilos de Liderança}

Nunes (2006) pesquisou sobre o estilo de liderança adotado pelas mulheres empreendedoras de Minas Gerais, notadamente as associadas ao Conselho da Mulher Empreendedora da Associação Comercial de Minas Gerais. O trabalho desenvolvido resultou na identificação do perfil médio das dirigentes como empreendedoras casadas, com média de dois filhos e formação acadêmica elevada.

Elas se sentem empreendedoras como resultado de sua criatividade, de sua habilidade para descobrir novas oportunidades e por sua capacidade em assumir riscos. $\mathrm{E}$ ainda, por saberem motivar seus colaboradores e buscarem realizar seus sonhos. Elas adotam o estilo de liderança voltado para pessoas sem, contudo, desconsiderar seu papel de cumpridora de metas, o que caracteriza um estilo de liderança também voltado para tarefas.

Esses são apenas alguns dos aspectos que possibilitam a compreensão de como o desempenho do papel empreendedor desempenhado por mulheres tem suscitado o interesse de diversos pesquisadores. Os autores se mostraram atentos às possíveis diferenças entre empreendedores e empreendedoras e quais dificuldades são encontradas por elas. Enfim, eles buscam compreender a inserção de mulheres em um papel que tradicionalmente era ocupado por homens.

\section{Método da Pesquisa}

A metodologia de pesquisa, para Minayo (2003), pode ser entendida como o caminho do pensamento a ser seguido. Ocupa um lugar central na teoria e trata-se basicamente do conjunto de técnicas a ser adotada para construir uma realidade. Como delineamento metodológico, esta pesquisa foi exploratória com método compreensões do empreendedorismo e do exercício do papel desempenhado por homens e mulheres em organizações. Revista de Empreendedorismo e Gestão de Pequenas Empresas, v. 2, n.2, p. 32-54, 2013. 
qualitativo. A pesquisa exploratória para Hair et al. (2005), quando bem conduzida, possibilita uma nova perspectiva para as percepções dos comportamentos dos pesquisados. Ou seja, as pesquisas exploratórias apresentam como principal objetivo, esclarecer, desenvolver e modificar conceitos e ideias, proporcionando uma visão geral do problema. Podem assumir várias formas, desde uma completa revisão de literatura que serve para a melhor interação sobre o assunto estudado, até entrevistas e grupos de foco que fornecerão dados específicos e detalhados do tema abordado.

O método qualitativo, para Vieira e Zouain (2004), garante a riqueza dos dados, permitindo ver um fenômeno na sua totalidade, e ainda facilita a exploração de contradições e paradoxos. Nesse sentido, o entendimento sobre empreendedorismo feminino, dentro do âmbito maior do empreendedorismo, foi desenvolvido neste estudo com as gestoras da associação definida como contexto de pesquisa.

Assim, a população em estudo abrangeu as 21 empresárias integrantes da CME desta associação, em março de 2008. Pela população ser reduzida, a amostra correspondeu ao número total dos elementos. Esta escolha foi intencional, não probabilística e de conveniência, de acordo com os objetivos da pesquisa.

O procedimento inicial de pesquisa ocorreu por meio telefônico com a CME, no sentido de obter os dados para um contato inicial com suas integrantes, como: correio eletrônico, telefone comercial e as empresas que representavam. Como resposta, a consultora enviou por correio eletrônico um quadro com as informações solicitadas que serviram para dar início a pesquisa. Esse procedimento foi realizado em agosto de 2008.

De posse dessas informações, foi enviado por correio eletrônico uma carta de apresentação da pesquisa e um questionário com questões fechadas e abertas que buscavam colher dados sobre as características pessoais e profissionais das empresárias. Os questionários preenchidos foram devolvidos também por correio

GOUVÊA, A. B. C. T.; SILVEIRA, A.; MACHADO. H. P. V Mulheres empreendedoras: compreensões do empreendedorismo e do exercício do papel desempenhado por homens e mulheres em organizações. Revista de Empreendedorismo e Gestão de Pequenas Empresas, v. 2, n.2, p. 32-54, 2013. 
eletrônico no prazo determinado de dez dias. Ressalta-se, porém, que algumas respondentes não preencheram todas as questões solicitadas.

A pesquisa do entendimento das gestoras sobre empreendedorismo foi realizada por meio de um painel com as respondentes que apresentaram características pessoais e profissionais mais compatíveis com o que preconiza a literatura para empreendedoras femininas. Este encontro foi realizado em fevereiro de 2009 na sede da associação com nove participantes. Para coletar esses dados foi adotada a técnica do focus group e na ocasião foi distribuído um roteiro norteador às participantes. A discussão foi filmada e depois trancrita, possibilitando a análise utilizada para este estudo. Buscando resguardar as identificações das respondentes, foram denominadas na pesquisa como $\mathrm{R} 1, \mathrm{R} 2, \ldots, \mathrm{R} 9$.

O focus group teve origem na sociologia e hoje é amplamente utilizado como técnica de pesquisa em diversas áreas de campos de ação. Dentro da ciência social, foi Robert Merton quem publicou o primeiro trabalho utilizando o focus group (MORGAN, 1997). É apropriada quando o objetivo é explicar como as pessoas consideram uma experiência, uma ideia ou um evento, visto que a discussão durante as reuniões é efetiva em fornecer informações sobre o que as pessoas sentem ou pensam, ou ainda sobre a forma como agem. $\mathrm{O}$ objetivo da discussão em grupo é obter o entendimento dos participantes sobre o tópico de interesse da pesquisa, não importando se é utilizado sozinho ou em conjunto com outros métodos.

Nesse caso, o focus group pode ser usado como uma pesquisa preliminar para preparar questões específicas em um grande projeto ou como uma pesquisa para esclarecer resultados de outros estudos (CRESWELL, 1994). O número de participantes dos grupos encontrados na literatura pode variar de seis a dez pessoas (MORGAN, 1997), ou oito a doze (KRUEGER; CASEY, 2000; HAIR et al., 2005). Os dados fundamentais produzidos por essa técnica foram transcritos das discussões do grupo, acrescidos das anotações do moderador.

GOUVÊA, A. B. C. T.; SILVEIRA, A.; MACHADO. H. P. V Mulheres empreendedoras: compreensões do empreendedorismo e do exercício do papel desempenhado por homens e mulheres em organizações. Revista de Empreendedorismo e Gestão de Pequenas Empresas, v. 2, n.2, p. 32-54, 2013. 
Tendo em vista o caráter indutivo da pesquisa, os dados coletados nas entrevistas do focus group foram analisados com base na técnica de análise de conteúdo (BARDIN, 1979; BAUER, 2002), classificando em categorias os significados similares. Para Bardin (1979, p. 42) a análise de conteúdo é compreendida como:

Um conjunto de técnicas de análise das comunicações visando obter, por procedimentos sistemáticos e objetivos do conteúdo das mensagens, indicadores que permitam a inferência de conhecimentos relativos ás condições de produção/ recepção (variáveis inferidas) destas mensagens.

Nesse sentido, o autor define a análise de conteúdo como uma maneira de analisar a comunicação obtida entre pessoas, dando importância ao conteúdo da mensagem adquirida. Vale dizer que o procedimento básico para esse tipo de análise diz respeito à definição de categorias pertinentes aos propósitos da pesquisa (VERGARA, 2006).

Para a definição das categorias neste estudo, optou-se pelo sistema aberto, onde elas são escolhidas durante 0 andamento da pesquisa sendo totalmente flexíveis, pois permite alterações até obter o resultado final (LAVILLE; DIONNE, 1999). A análise de conteúdo possibilitou uma leitura profunda das comunicações, indo além da leitura aparente. As três fases propostas por Bardin (1979) foram adotadas.

\section{Análise e Interpretação dos Dados}

Os aspectos que compõem o perfil pessoal e profissional das empresarias da CME, bem como os resultados encontrados no focus group são relatados a seguir. 


\section{Características Pessoais e Profissionais}

Apenas $15 \%$ das 21 mulheres que participaram desta fase da pesquisa têm idade inferior a 40 anos. As demais (75\%) encontram-se entre 41 e 60 anos e $10 \%$ acima de 61 anos. Quando ao número de filhos predominou um, dois ou três filhos, $95,2 \%$. O estado civil predominante $(85,8 \%)$ é casado.

Quanto à formação acadêmica, 95,2\% possuem nível superior. Destas, 76,1\% são especialistas em Gestão de Negócio, Marketing, Gestão Empresarial, Contabilidade, Auditoria, Finanças, Comunicação e Filosofia da Educação. O tempo dedicado ao empreendimento para $90,4 \%$ dos casos variou entre 7 e 14 horas diárias. Todas são responsáveis por $50 \%$ a $100 \%$ da renda familiar.

Quanto às razões para criação do negócio, 28,5\% tornaram-se empreendedoras por iniciativa própria e oportunidade e $71,5 \%$ disseram ser por acaso, forçadas ou por outros motivos. As principais dificuldades para a gestão de uma empresa se concentram, em sua maioria, em obter financiamento $(23,8 \%)$ ou na falta de tempo para se dedicar à empresa ou à família $(23,8 \%)$. Conciliar trabalho e família também foi apontado como dificuldade $(9,5 \%)$.

Do total das empresas, $66,6 \%$ tem mais do que dez anos. A maioria destas empresas está concentrada no setor de serviços $(66,6 \%)$, seguido do comércio $(19 \%)$ e da indústria (14,2\%). Sobre a atuação das empresas, $76,1 \%$ se dedicam ao mercado interno, sendo que apenas duas empresas atuam no mercado externo. Os ramos de atividades se voltam para: acessórios pessoais, calçados e vestuários; alimentação; beleza, saúde e produtos naturais; comunicação, informática e eletrônicos; contabilidade empresarial; educação e treinamento; metal mecânico; negócios, serviços e conveniências; produtos químicos; e serviços automotivos.

Quanto à participação societária, 61,9 \% são sócias majoritárias nas empresas que administram. Apenas $14,2 \%$ têm menos de $50 \%$ de participação na sociedade. Isto mostra que a maioria das empresárias não só participam das empresas, como mantém o controle acionário. O maior número de empresas compreensões do empreendedorismo e do exercício do papel desempenhado por homens e mulheres em organizações. Revista de Empreendedorismo e Gestão de Pequenas Empresas, v. 2, n.2, p. 32-54, 2013. 
$(28,5 \%)$ possui entre 6 a 15 funcionários. O faturamento do maior número de empresas (19\%) está entre 500 mil e 1 milhão de reais por ano. Acima de cinco milhões figuram 14,2\%. Uma das empresas fatura acima de 5 milhões de reais por ano. $38 \%$ das empreendedoras não quiseram informar o faturamento das empresas.

\section{Resultados do Focus Group}

Os principais resultados das verbalizações das nove empresárias participantes do estudo levado a efeito por meio da técnica do focus group mostra que há entendimento sobre empreendedorismo. A resposta imediata da R8 "é estar disposta a fazer algo". Completada pelas demais participantes, as respostas indicam que é ter uma ideia e a colocar em prática, ou seja, agir em função de uma ideia, "uma ideia e uma ação" (R1). A segunda verbalização indicou a importância de transformar desafios, um problema ou uma necessidade em oportunidade (R3).

Outro aspecto foi ainda "ter visão de algo novo, diferente", como representação de empreendedorismo (R5). Ainda nessa linha de raciocínio, a visão da R7 complementa este ponto citando Filion (1999), e afirmando que o empreendedorismo alia a visão de uma oportunidade à criatividade. Inovação é inerente ao empreendedorismo, complementa esta respondente.

Os principais resultados das verbalizações das participantes do focus group, inicialmente quanto à compreensão do empreendedorismo, foram sintetizados na Figura 1.

GOUVÊA, A. B. C. T.; SILVEIRA, A.; MACHADO. H. P. V Mulheres empreendedoras: compreensões do empreendedorismo e do exercício do papel desempenhado por homens e mulheres em organizações. Revista de Empreendedorismo e Gestão de Pequenas Empresas, v. 2, n.2, p. 32-54, 2013. 


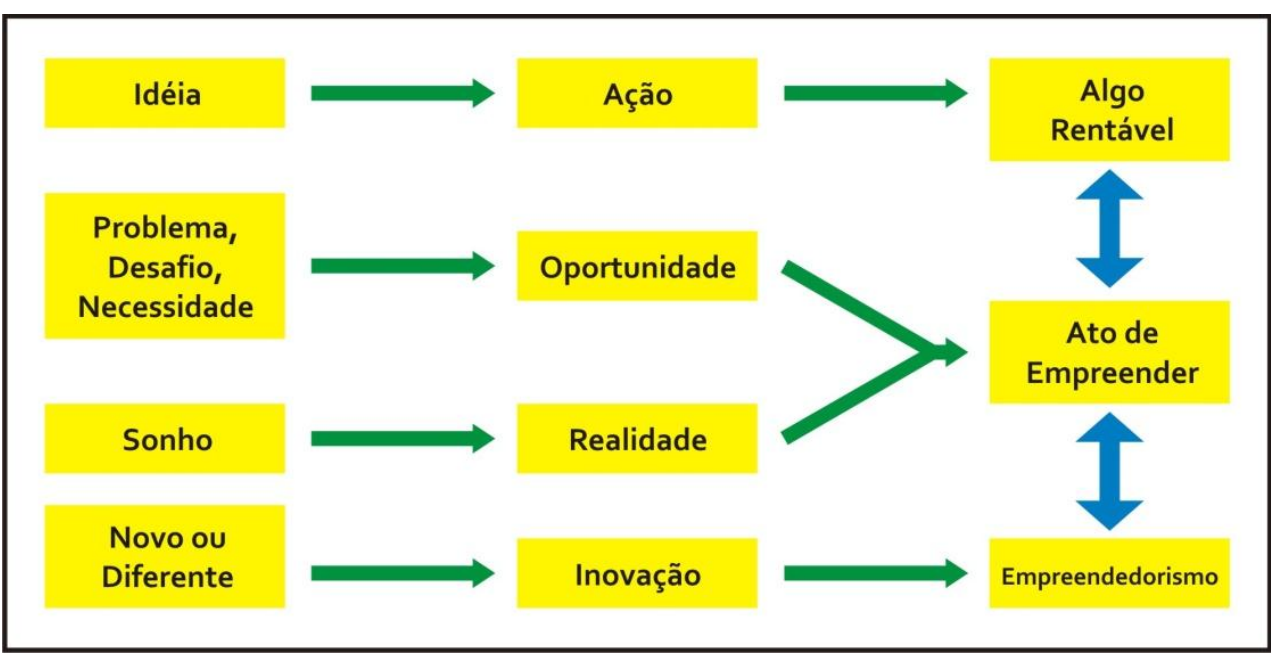

Figura 1: Compreensões do Empreendedorismo por Mulheres Empreendedoras.

Fonte: Os Autores (2012)

Os elementos que aparecem nos entendimentos das empreendedoras coincidem com os aspectos apontados na literatura (FILION, 1999; BARON, SHANE, 2007), principalmente quanto a ideia ou visão, criação de valor (algo rentável) e inovação. Todavia, nota-se que as empreendedoras não associam o empreendedorismo a um processo, como salientam Baron e Shane (2007), que se inicia com a criação de um negócio, mas amplia-se até o processo de gestão e crescimento das empresas.

Um dado interessante obtido é a compreensão conjugada do empreendedorismo por necessidade e por oportunidade, como mostra o seguinte trecho: "Porque na maioria das vezes o empreendedor vem de uma necessidade...". "Mas aí eu diria que as necessidades levam às oportunidades." (R4). Essa compreensão foi reforçada em outra manifestação: "Porque às vezes você se põe numa necessidade financeira até, uma questão de sobrevivência, e aí não necessariamente... a pessoa não nasce empreendedor. Ele pode tornar-se um empreendedor". (R3). Nesse sentido, as manifestações foram representadas na Figura 2.

GOUVÊA, A. B. C. T.; SILVEIRA, A.; MACHADO. H. P. V Mulheres empreendedoras: compreensões do empreendedorismo e do exercício do papel desempenhado por homens e mulheres em organizações. Revista de Empreendedorismo e Gestão de Pequenas Empresas, v. 2, n.2, p. 32-54, 2013. 


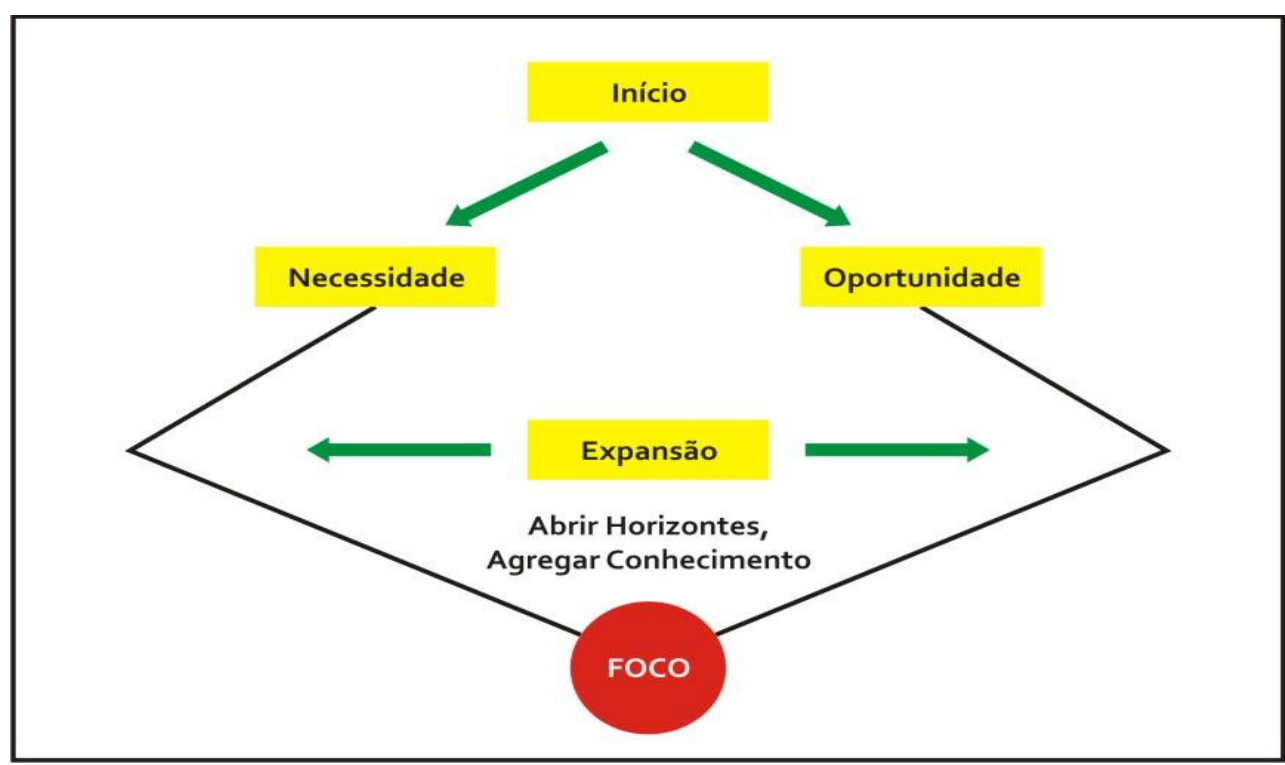

Figura 2: Compreensões de Empreendedorismo: Necessidade ou Oportunidade?

Fonte: Os Autores (2012).

Como as manifestações sobre possíveis diferenças de gênero no exercício do papel empreendedor não emergiram, solicitou-se às participantes que se manifestassem sobre o assunto. Sobre essa questão, identificaram-se diferenças visualizadas pelas empreendedoras nos seguintes aspectos: exercício de múltiplos papéis pelas mulheres; as mulheres têm menor preparo e/ou necessitam de flexibilidade de horários; as mulheres empreendem para complementar a renda; têm necessidade de jornada dupla e com isso precisam ser mais criativa. Quanto ao poder, para elas a mulher partilha o poder e as informações, mas o homem centraliza-o. A mulher tem maior tendência em procurar agradar e propiciar satisfação a funcionários, clientes e fornecedores e, nesse sentido, prende-se mais a detalhes. A síntese está apresentada na figura 3. 


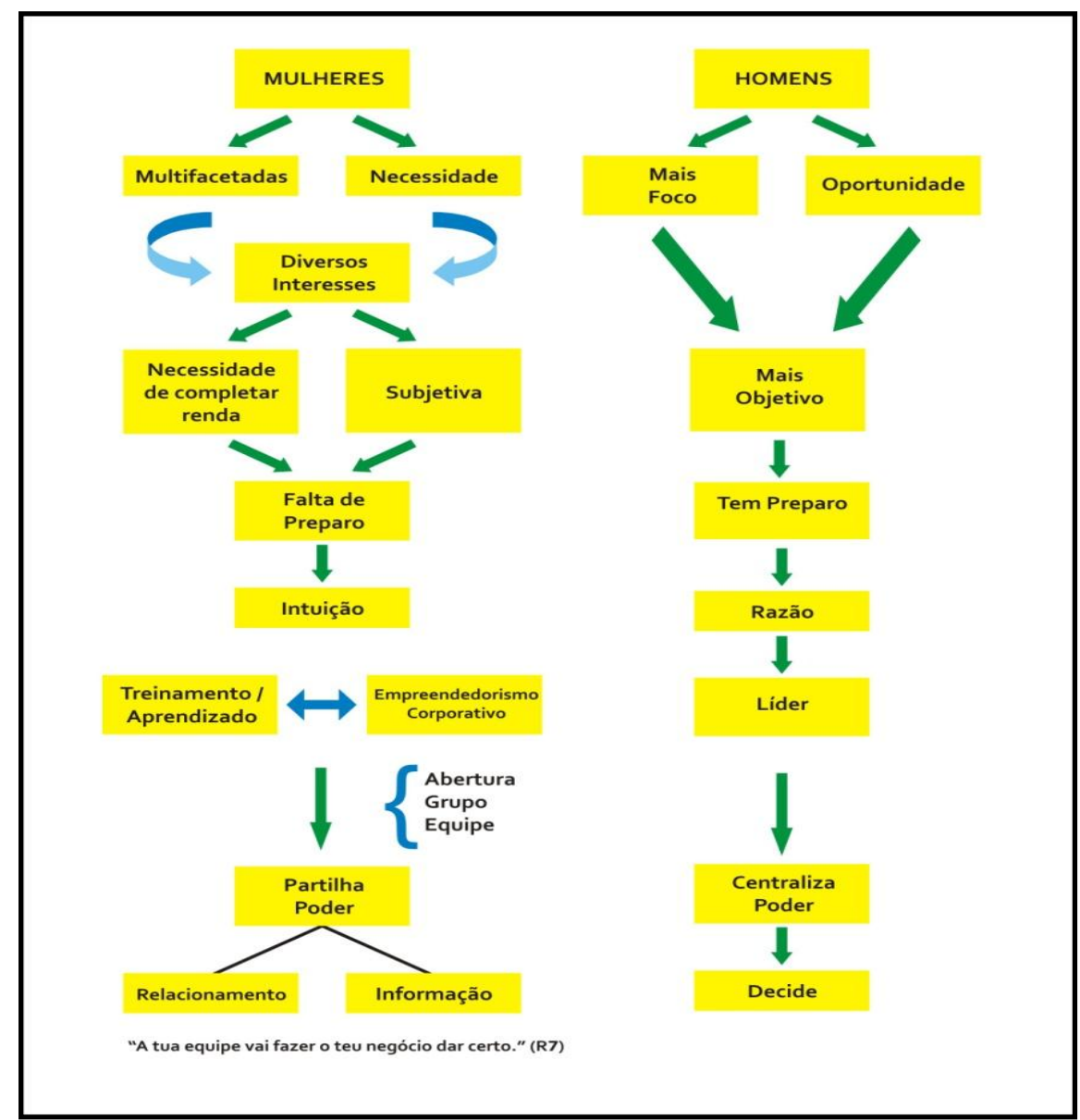

Figura 3: Compreensões de Homens e Mulheres Empreendedoras

Fonte: Os Autores (2012)

Os resultados dos entendimentos sobre empreendedorismo pelas integrantes do focus group evidenciam que as empreendedoras têm compreensão do empreendedorismo no início do processo, envolvendo aspectos como visão, intuição, criatividade, inovação, oportunidade e criação de valor. Contudo, outras fases do processo não foram mencionadas, o que mostra um entendimento apenas sobre o início do processo. Elas não fazem distinção entre empreender por necessidade ou por oportunidade, como a classificação adotada em alguns estudos, por exemplo, o GEM (2008).

GOUVÊA, A. B. C. T.; SILVEIRA, A.; MACHADO. H. P. V Mulheres empreendedoras: compreensões do empreendedorismo e do exercício do papel desempenhado por homens e mulheres em organizações. Revista de Empreendedorismo e Gestão de Pequenas Empresas, v. 2, n.2, p. 32-54, 2013. 
O aspecto mais importante do estudo foram as manifestações sobre diferenças de gênero no desempenho do papel mostradas na figura 3. Esses aspectos diferenciados, na visão delas, reforçam resultados de estudos anteriores. Mas ao mesmo tempo, essa compreensão diferenciada sobre o desempenho do papel por homens e mulheres reitera a necessidade de estudos adicionais com empreendedoras.

\section{Conclusão}

As características das empreendedoras que integraram esta pesquisa podem ser resumidas quanto à idade: predomínio entre 41 e 60 anos, sendo que apenas três estão abaixo da faixa dos 40 anos, em sua maioria casadas e com filhos. No que se refere ao tempo que dedicam à empresa (diariamente), em sua maioria, fica entre 7 a 14 horas. Quanto ao orçamento familiar, $48 \%$ das empresárias participam em média com $50 \%$ do valor no orçamento familiar. As empresas que elas gerenciam, embora na sua maioria tenham mais do que 10 anos no mercado, são micro e pequenas organizações.

A área de atuação predominante foi a de serviços, voltada ao mercado interno. Sobre a forma societária da maioria das empresas, 38\% é composta de 50 a $74 \%$, prevalecendo a presença de dois sócios (52\%). O número de unidades foi outro fator que auxiliou na classificação das empresas, sendo que $48 \%$ possuem apenas uma unidade, com uma média entre 6 a 15 funcionários (33\%).

A metodologia do focus group mostrou-se adequada para a finalidade deste estudo, bem como o número de empreendedoras que participaram. Acredita-se que um número maior do que dez propicie dificuldades aos pesquisadores em acompanhar e possibilitar a expressão de todos os participantes.

Quanto ao entendimento sobre empreendedorismo, a criação de valor, oportunidade e inovação, além da transformação de sonho em ação são elementos apontados na literatura e mencionados pelas empreendedoras.

GOUVÊA, A. B. C. T.; SILVEIRA, A.; MACHADO. H. P. V Mulheres empreendedoras: compreensões do empreendedorismo e do exercício do papel desempenhado por homens e mulheres em organizações. Revista de Empreendedorismo e Gestão de Pequenas Empresas, v. 2, n.2, p. 32-54, 2013. 
No tocante ao empreendedorismo exercido por homens e mulheres, elas visualizaram dois caminhos distintos, sendo um mais objetivo para os homens e outro envolvendo o exercício de múltiplos papéis para as mulheres. Isto mostra que para os homens os universos públicos e privado encontram-se separados na visão delas, enquanto que para as mulheres os dois mundos devem caminhar simultaneamente, exigindo flexibilidade e criatividade.

Outro ponto importante na visão distinta entre o exercício do papel empreendedor por homens e por mulheres é a maior centralização pelos homens e a partilha da informação pelas mulheres, tal como o resultado encontrado por Machado (1999). Esses resultados instigam a necessidade de compreender, na visão de homens empreendedores, se há distinções entre o exercício do papel empreendedor por homens e por mulheres, para comparar com os resultados encontrados neste estudo.

No tocante ao empreendedorismo feminino e masculino, a principal diferença apontada diz respeito ao foco. Para as empresárias, o homem é mais dirigido, mais preparado e objetivo, já as mulheres caminham por vias paralelas, são mais flexíveis, têm menos preparo e em função de terem de desempenhar diversos papéis (mãe, esposa, empresária, entre outros), são mais versáteis e criativas, obtendo soluções diferenciadas para as mesmas situações. Outro ponto importante é o fato do homem ser mais centralizador enquanto a mulher partilha informação, se preocupa mais com sua equipe por saber que a equipe é que trará o resultado para a empresa, por isso, a importância dos objetivos serem compartilhados. Ainda quanto à questão sobre possíveis diferenças entre empreendedorismo feminino e masculino, fato que também foi confirmado, as empresárias dizem que as diferenças são sutis e estão mais relacionadas ao estilo de gestão e visão, pois para elas, o espaço existe para todos, basta saber aproveitar, independente de gênero.

Ainda na visão das respondentes, o empreendedorismo tem duas fontes principais: por necessidade e motivacional, sendo que ambos variam do contexto em que o indivíduo está inserido.

GOUVÊA, A. B. C. T.; SILVEIRA, A.; MACHADO. H. P. V Mulheres empreendedoras: compreensões do empreendedorismo e do exercício do papel desempenhado por homens $\mathrm{e}$ mulheres em organizações. Revista de Empreendedorismo e Gestão de Pequenas Empresas, v. 2, n.2, p. 32-54, 2013. 
Esse estudo possui algumas limitações em função do número de respondentes ser pequeno, bem como devido ao método qualitativo utilizado para a última etapa da pesquisa. Porém, pode ser utilizado como uma abordagem inicial para uma pesquisa mais abrangente, desdobrando o estudo para outras associações nacionais ou até mesmo internacionais com características semelhantes. A adoção de diferentes metodologias, tanto quantitativas como qualitativas, seria válido para complementar os estudos neste foco.

Por derradeiro cumpre dizer que estudos similares podem ser realizados em associações ou núcleos com participação de homens e mulheres, bem como com profissionais intraempreendedores, buscando consolidar o conhecimento no assunto, tanto do ponto de vista teórico como da prática.

\section{Referências:}

BARDIN, L. Análise de conteúdo. Lisboa: Edições 70, 1979.

BARON, R. A.; SHANE, S. A. Empreendedorismo: uma visão do processo. São Paulo: Thomson, 2007.

BAUER, M. V. Análise de conteúdo clássica: uma revisão. In: BAUER, M. W; GASKELL, G. Pesquisa qualitativa com texto, imagem e som: um manual prático. Petropolis: Vozes, 2002.

CARLAND, J; CARLAND, J.; CARD, R. The multi-facets of female entrepreneurship: their dreams and their realities. Paper presented at the World Conference of the International Council for Small Business, 50p, Washington, DC, 2005. Proceedings... Washington, DC, 2005.

CARTER, S; ROSA, P. The financing of male-and-female-owned businesses'. Entrepreneurship and Regional Development, v. 10, p. 225-241, 1998.

CRESWELL, J. W. Research design: qualitative \& quantitative approaches. Thousand Oaks, CA: SAGE Publ., 1994.

GOUVÊA, A. B. C. T.; SILVEIRA, A.; MACHADO. H. P. V Mulheres empreendedoras: compreensões do empreendedorismo e do exercício do papel desempenhado por homens e mulheres em organizações. Revista de Empreendedorismo e Gestão de Pequenas Empresas, v. 2, n.2, p. 32-54, 2013. 
DHALIWAL, S. Winning women: UK female entrepreneurs. In: INTERNATIONALIZING ENTREPRENEURSHIP EDUCATION AND TRAINING, 2006, São Paulo. Proceedings... São Paulo: FGV, 2006.

FILION, L. J. Empreendedorismo: empreendedores e proprietários-gerentes de pequenos negócios. Revista de Administração da USP. São Paulo, v. 34, n. 2, abr./jun., 1999.

GLOBAL ENTREPRENEURSHIP MONITOR. Empreendedorismo no Brasil 2007: relatório nacional. Curitiba: IBQP, 2008.

HAIR JR., J. F. et al. Fundamentos de métodos de pesquisa em administração. Porto Alegre: Bookman, 2005.

KRUEGER, R. A.; CASEY, M. A. Focus groups: a practical guide for applied research. 3. ed. Thousand Oaks: Sage, 2000.

LANGOWITZ, N.; MINNITI, M. The entrepreneurial propensity of women. Entrepreneurship Theory and Practice, v. 31, n. 3, p. 341-364, may, 2007.

LAVILLE, C; DIONNE, J. A construção do saber: manual de metodologia da pesquisa em ciências humanas. Porto Alegre: Artmed, 1999.

LEITE, R. C. De executivo a empresário: como realizar o seu ideal de segurança e independência. Rio de Janeiro: Campus, 1998.

MACHADO, H. V. Tendências do comportamento gerencial da mulher empreendedora. In: ENCONTRO NACIONADO DA ASSOCIAÇÃO NACIONAL DE PÓS-GRADUAÇÃO E PESQUISA EM ADMINISTRAÇÃO, 23, 1999, Foz do Iguaçu. Anais... Rio de Janeiro: Anpad, 1999.

Female and male entrepreneurs managerial behaviour: a Brazilian study. International Management, Montreal, v. 7, n. 1, 2002.

MACHADO, H. V. et al. Significados de sucesso e fracasso nos negócios: o que dizem mulheres empreendedoras In: ENCONTRO NACIONADO DA ASSOCIAÇĀO NACIONAL DE PÓS-GRADUAÇÃO E PESQUISA EM ADMINISTRAÇÃO, 32, 2008, Rio de Janeiro. Anais... Rio de Janeiro: Anpad, 2008.

GOUVÊA, A. B. C. T.; SILVEIRA, A.; MACHADO. H. P. V Mulheres empreendedoras: compreensões do empreendedorismo e do exercício do papel desempenhado por homens e mulheres em organizações. Revista de Empreendedorismo e Gestão de Pequenas Empresas, v. 2, n.2, p. 32-54, 2013. 
MACHADO, $\mathrm{H} \mathrm{V}$ et al. Female and male entrepreneurs managerial behaviour: a brazilian study. International Management, Montreal, v. 7, n. 1, 2002.

MANOLOVA, T. S.; BRUSH, C. G.; EDELMAN, L. F. What do women entrepreneurs want? Strategic Change, v. 17, n. 3/4, p. 69, 2008.

MANOLOVA, T. S. et al. The Differential Effect of Men and Women Entrepreneurs' Human Capital and Networking on Growth Expectancies in Bulgaria. Entrepreneurship Theory and Practice, v. 31, n. 3, p. 407-426, 2007.

MINAYO, M. C. S. (Org.) Pesquisa social: teoria, método e criatividade. 22. ed. Rio de Janeiro: Vozes, 2003.

MORGAN, D. L. Focus group as qualitative research. Beverly Hills: SAGE Publ., 1997.

MORRIS, M. H. et al. The dilemma of growth: understanding venture size choices of women entrepreneurs. Journal of Small Business Management, v. 44, n. 2, p. 221244, Apr., 2006.

NEIDER, L. A preliminary investigation of female entrepreneurs in Florida. Journal of Small Business Management, v. 25, n. 3, p. 22-29, 1997.

NUNES, J. L. F. O empreendedorismo feminino e o estilo de liderança no conselho da mulher empreendedora da associação comercial de Minas. 2006. Dissertação (Mestrado Profissional em Administração) - Faculdade de Estudos Administrativos de Minas Gerais. Minas Gerais, 2006. Disponível em: <http://www.fead.br/ebooks/DOCSTCCMONO/Jose\%20luiz\%20Fernandes.pdf>. Acesso em: 15 mar. 2009.

RIBEIRO, J. A mulher e o voto: Disponível em:

<http://www.al.sp.gov.br/web/eleicao/mulher_voto.htm>. Acesso em: 15 set. 2008.

SCHWARTZ, E, B. Entrepreneurship: a new female frontier. Journal of Contemporary Business, v. 5, n. 1, p. 47, 1976

SILVEIRA, A.; GOUVÊA, A. B. C. T; HOELTGBAUM, M. Empreendedorismo feminino: características, considerações e entendimentos de mulheres gerentes de

GOUVÊA, A. B. C. T.; SILVEIRA, A.; MACHADO. H. P. V Mulheres empreendedoras: compreensões do empreendedorismo e do exercício do papel desempenhado por homens e mulheres em organizações. Revista de Empreendedorismo e Gestão de Pequenas Empresas, v. 2, n.2, p. 32-54, 2013. 
micro e pequenas empresas de Santa Catarina, Brasil. In: SEMINÁRIOS EM ADMINISTRAÇÃO FEA/USP, 11, São Paulo, 2008. Anais... São Paulo: FEA/USP, 2008.

TAN, J. Breaking the "Bamboo Curtain" and the "Glass Ceiling": the experience of women entrepreneurs in high-tech industries in an emerging market. Journal of Business Ethics, v. 80, p. 547-564, 2008.

VERGARA S. C. Métodos de pesquisa em administração. 2. ed. São Paulo: Atlas, 2006.

VIEIRA, M. M. F.; ZOUAIN, D. M. (Orgs.) Pesquisa qualitativa em administração. Rio de Janeiro: Editora FGV, 2004.

WATSON, J. Failure rates for female controlled businesses: are they any different? Journal of Small Business Management, v. 41, n. 3, p. 262-277, 2003.

Artigo recebido em: 08/06/2013. Aprovado em: 03/08/2013 